\title{
Geometalurgia y el futuro de la minería digital en el Perú
}

\author{
Geometallurgy and the future of digital mining in Peru \\ Jesús Alberto Torres Guerra ${ }^{1}$, Denis Mejía Cáceres ${ }^{2, a}$, Patrick Moreyra Ramos ${ }^{2, b}$, \\ Jairo Oré Grados ${ }^{2, c}$, Santos Oscco Barrientos ${ }^{2, d}$
}

Recibido: 26/10/2020 - Aprobado: 13/04/2021 - Publicado: 18/06/2021

\begin{abstract}
RESUMEN
En la actualidad, estamos enfrentando la llamada revolución industrial 4.0, que abarca la aparición de nuevas tecnologías como la robótica, sistemas de aprendizaje automático, la inteligencia artificial, redes de alto rendimiento, multi-cloud, entre otros. Estos desarrollos, como lo es el aprendizaje automático (machine learning), se presenta como una oportunidad para la industria minera. En especial, para el campo de la Geometalurgia, que requiere la integración de modelos predictivos en toda la cadena de valor de la minería (Modelo geometalúrgico). Este panorama, proporciona un enfoque innovador para impactar significativamente en la toma de decisiones, que conllevan a mejorar la planificación y optimización de los procesos. Este artículo aborda el estado del arte de la Geometalurgia en la era digital, y nos presenta los avances tecnológicos utilizados en las industrias mineras. Así mismo, se presenta la situación actual de la Geometalurgia en las minas peruanas.
\end{abstract}

Palabras claves: Revolución industrial 4.0; aprendizaje automático; Geometalurgia; modelo geometalúrgico; optimización de procesos.

\begin{abstract}
Today, we are facing the fourth industrial revolution, which involves the emergence of new technologies such as robotics, machine learning systems, artificial intelligence, high-performance networks, and multi-cloud, among others. These developments, such as machine learning (machine learning), present themselves as an opportunity for the mining industry. In particular, for the field of Geometallurgy, which requires the integration of predictive models throughout the mining value chain (Geometallurgical Model). This scenario provides an innovative approach to significantly impact decisionmaking, leading to improved planning and optimization of processes. This article addresses the state of the art of Geometalurgia in the digital age, and presents the technological advances used in the mining industries. Likewise, the current situation of Geometalurgia in the Peruvian mines is presented.
\end{abstract}

Keyword: Industrial revolution 4.0; machine learning; geometallurgy; geometallurgical model; process optimization.

\footnotetext{
1 Docente, Universidad Nacional Mayor de San Marcos, Unidad de Posgrado. Lima, Perú.

E-mail: jesus.torres5@unmsm.edu.pe - ORCID: https://orcid.org/0000-0001-8186-5249

2 Universidad Nacional Mayor de San Marcos, Facultad de Ingeniería Geológica, Minera, Metalúrgica y Geográfica, E. P. Ingeniería Geológica. Lima, Perú.

a E-mail: denisarmando@hotmail.com - ORCID: https://orcid.org/0000-0001-8175-4426

b E-mail: patrickmoreyra@outlook.com - ORCID: https://orcid.org/0000-0002-0902-0660

c E-mail: jairooregrados@hotmail.com -ORCID: https://orcid.org/0000-0001-5432-1086

d E-mail: osccoenrique@gmail.com - ORCID: https://orcid.org/0000-0003-3264-4604
} 


\section{INTRODUCCIÓN}

\subsection{La minería digital y la Geometalurgia}

Se conoce como Minería Digital 4.0 a la cuarta revolución industrial aplicada a la minería. Este concepto hace referencia a las innovaciones tecnológicas y su implementación en minería.

La implementación de tecnologías permite mejorar el desempeño de las operaciones en la mina, en todas sus áreas, desde producción hasta medio ambiente y seguridad.

Teniendo en cuenta las diversas definiciones y argumentos académicos utilizados para describir las tres primeras revoluciones industriales, se considera que a principios de este siglo se comenzó de una cuarta revolución industrial, basándose en la revolución digital. Se caracteriza por un internet más ubicuo y móvil, por sensores más pequeños y potentes que son cada vez más baratos, y por la inteligencia artificial y el aprendizaje de la máquina (Klaus Schwab, 2017).

La Geometalurgia es la ciencia que estudia, asocia y aplica las disciplinas de geología, minería y metalurgia para generar como producto final el "modelo geometalúrgico", el cual será un modelo predictivo que permita crear valor a la empresa o proyecto, prediciendo el comportamiento de los minerales cuando estos se procesen en la planta metalúrgica (Dominy et al., 2018).

Koch 2019, propone en su tesis de doctorado un flujograma de trabajo que debe considerarse para la elaboración del modelo geometalúrgico (Ver Figura 1).
En todas las empresas mineras hay trabajos que se desarrollan con la colaboración de grupos multidisciplinarios. Por ejemplo, uno de los principales inputs del planeamiento de minado es el modelo de bloques. A pesar de la buena elaboración y ejecución (por parte de Geología y Planeamiento-Mina), se reportan problemas al momento del procesamiento del ROM (Planta de procesos), debido a que el modelo de bloques no integra las informaciones metalúrgicas y por ende el comportamiento de los minerales es impredecible.

La Geometalurgia, resuelve este problema al integrar las informaciones de geología, minería y metalurgia en el modelo geometalúrgico, con el cual es factible predecir el comportamiento del ROM en la planta.

El futuro nos presentará yacimientos más complejos y desafiantes. En esta realidad, la Geometalurgia, por su naturaleza al manejar una gran cantidad de datos, permite la integración de la incertidumbre, la variabilidad y los factores externos, en la cual serán determinantes para evaluar la rentabilidad y la sostenibilidad de un proyecto minero.

El crecimiento a pasos agigantados de la era digital (como es el caso de la inteligencia artificial) en diversas industrias, avizoran a la Geometalurgia más moderna y avanzada. En nuestro país, aun este tema no está muy desarrollado, pero existen empresas mineras que han implementado o están implementado poco apoco esta ciencia, que les ha permitido anticiparse a resolución de problemas como dureza, recuperación, mantenimiento de equipos, entre otros.

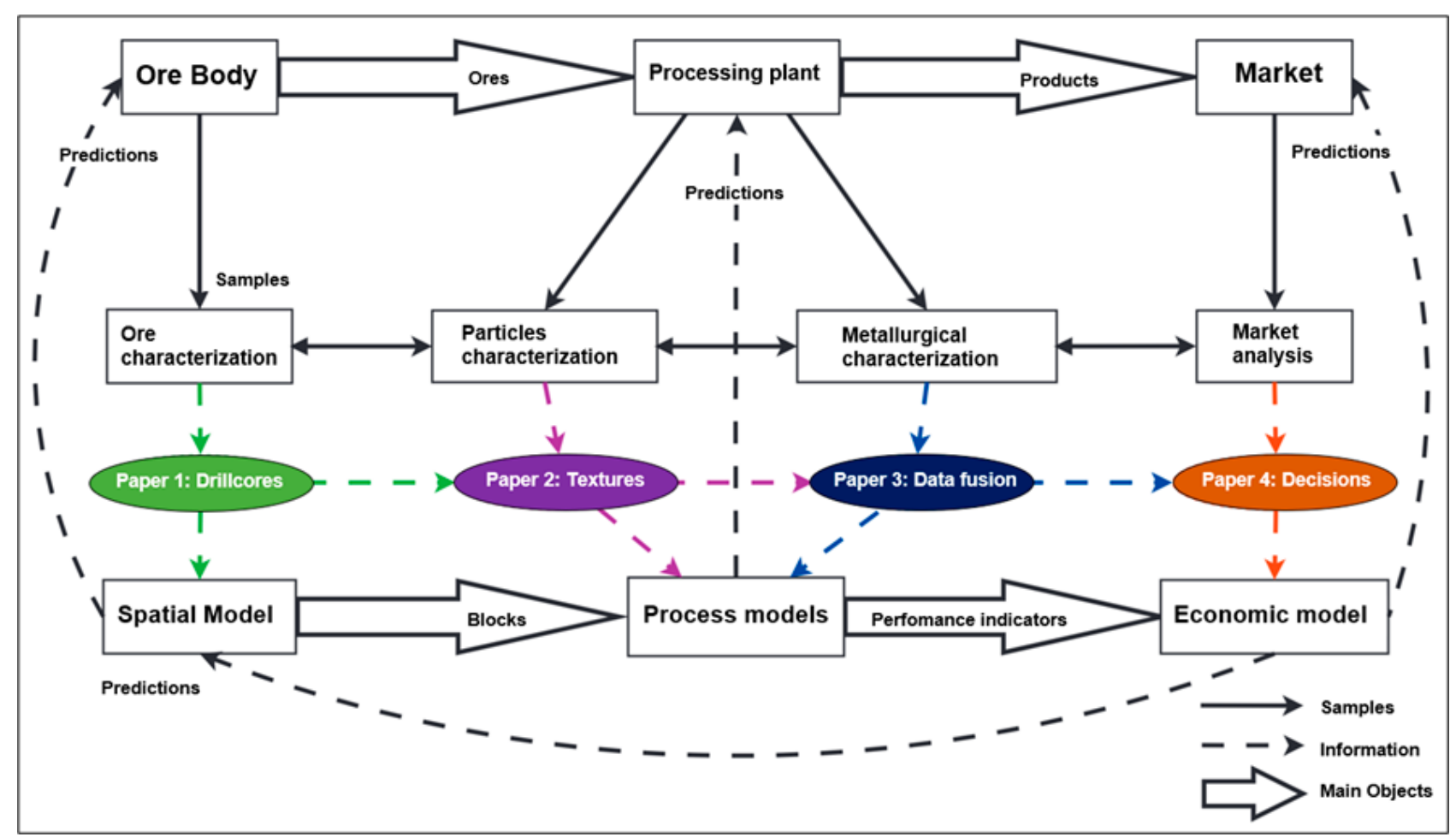

Figura 1. Computational methods and strategies for geometallurgy entire workflow in geometallurgy (Koch, 2019) 
Ante este panorama, serán cada vez más los profesionales, que deberán incluir en sus experiencias convencionales, las habilidades técnicas de análisis de datos y aprendizaje automático. Los cuales, a partir de sus conocimientos integrales, buscarán producir planes de mina de corto, mediano y largo plazo más efectivos y dinámicos. Además, de información en tiempo real y que permita realizar reconciliaciones automatizadas.

De esta manera, se busca cambiar el paradigma de trabajo en nuestro país y tener una cultura de mayor planificación y compromiso de responsabilidad del impacto ambiental. Por ello, es imprescindible, a través de la Geometalurgia, comprender desde exploración las características mineralógicas, la eficiencia del procesamiento de esos minerales y los efectos secundarios al ser procesados (minerales presentes en los relaves).

\section{MÉTODOS}

La metodología aplicada en la presente investigación es no experimental del tipo descriptiva, ya que se describe la importancia de la geometalurgia tanto con la finalidad de mejorar los procesos operativos, la mejora de la rentabilidad de las unidades mineras e incluso proyectarla en el futuro próximo a la era digital que en el mundo ya se aplica y en el Perú nos encontramos haciendo esfuerzos por ir aplicándola en todo el ciclo minero.

Además, se presentan una recolección de casos de empresas mineras en el Perú, que han tenido éxito con la implementación de nuevas tecnologías, y se detalla algunas otras en el mundo que aún nos falta adaptar en las diversas áreas de la cadena de valor de la minería, como son: la analítica de datos en tiempo real, integración de sistemas y conexión de redes, el manejo de equipos autónomos, uso de softwares y drones de última generación, entre otros. Es por ello, que contar con una minería hiperconectada, cobra mayor significado y relevancia.
Lo que se espera a través de este estudio, es que las empresas en nuestro país puedan seguir sumando esfuerzos y adaptarse rápidamente a estos cambios tecnológicos, ya que también con la llegada de la tecnología $5 \mathrm{G}$ en diversos sectores, se pueda dar un salto exponencial y llevar en su máxima expresión el concepto de minería 4.0.

\section{RESULTADOS}

\subsection{Minería digital en geología}

Es importante conocer las posibilidades que nos ofrecen los nuevos métodos de adquisición de datos; a través de satélites, la Geoquímica, y en especial, las técnicas de explotación, manipulación y representación de la información mediante el uso de la tecnología digital y la posibilidad de representar los datos mediante técnicas y software de 3D. De esta forma, poder validar así los modelos geológicos (Ver Figura 2).

\subsubsection{Integración de la base de datos}

La base de datos nos permite almacenar grandes cantidades de información geológica permitiéndonos organizar, auditar y estandarizar.

En la actualidad, los datos han pasado de ser escasos a ser muy abundantes, lo cual ha permitido la aparición y desarrollo de herramientas de análisis de datos como lo es el machine learning.

Cada vez los hallazgos de yacimientos son más difíciles o éstos presentan gran variabilidad, dando lugar al almacenamiento de gran cantidad de datos que rebasan las capacidades de los geólogos tradicionales. Es por ello, que el machine learning es una de las herramientas que está tomando mucho valor en la minería peruana, debido a sus metodologías para gestionar y analizar datos. De esta manera, influye directamente en la productividad y en la toma de mejores decisiones.

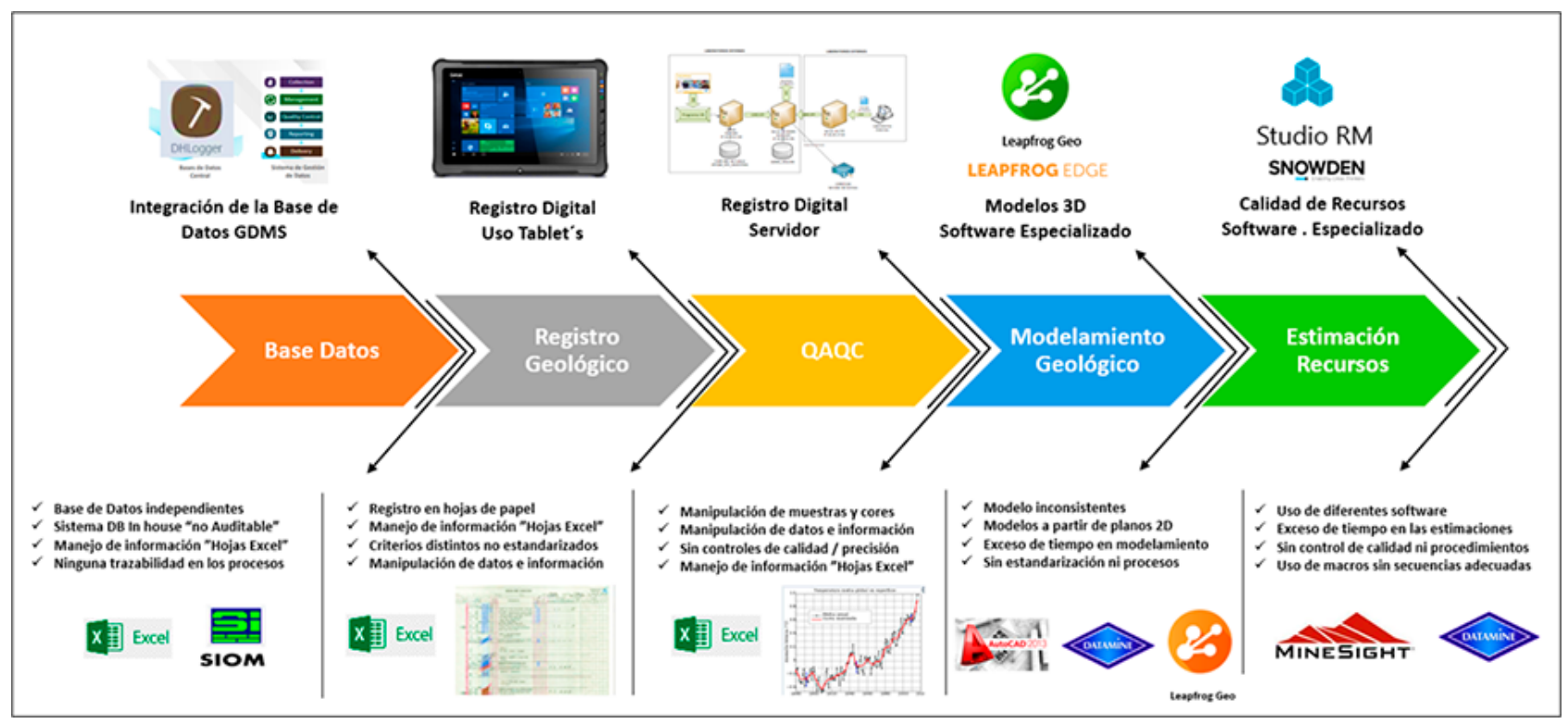

Figura 2. Proceso geológico y mejoras en sus etapas. (Fuente: Elaboración propia) 
Por otro lado, es importante que la información se encuentre al alcance de todos. Cada vez se hace más necesario, el manejo de los datos en la nube, que permita un fácil acceso en tiempo real y procesarla para su evaluación en beneficio del negocio minero en general.

\subsubsection{Registro geológico}

El Logueo Geológico y Geomecánico de testigos y/o detritos de perforación, es uno de los aspectos más importantes dentro del proceso geológico y en la exploración. En la actualidad existen equipamientos que realizan un logueo en laboratorios móviles, y a través del escaneo de testigos, procesan un mapeo mineralógico mediante espectroscopia de reflectancia, imágenes visuales y perfilador láser 3D para mapear la mineralogía, geoquímica y morfología textural del testigo. Se rastrean la mena y la ganga, mientras que las variables texturales y mineralógicas revelan propiedades mecánicas claves de las rocas.

El registro geológico se complementa con las pruebas de desviación del pozo, es necesario saber el inicio y el fin en especial en pozos mayores a $100 \mathrm{~m}$ de profundidad, este dato es muy importante en la elaboración del modelamiento geológico (Ver Figura 3). En la década de los 90, para medir la inclinación y el azimut del pozo perforado, se utilizaba los métodos de la prueba ácida y el reloj Tropari; en la cual la recolección de los resultados se hacía de manera manual. Es a partir del año 2000, que se emplean nuevas tecnologías digitales en la recolección de datos de inclinación y azimut. En el mercado, los más conocidos son:

- Multishot y GyroReflex de la compañía sueca Reflex.

- Multishot Gyroscopic STP de la compañía sueca Stockholm Precision Tools
- Deviflex, equipos de tensión-elongación de la compañía sueca Devico.

\subsubsection{Control y Aseguramiento de Calidad $Q A / Q C$}

Se realizan labores de muestreo procedentes de Mina y Perforación Diamantina, las cuales son registradas en una base de datos.

El aseguramiento de la calidad se plasma mediante la elaboración e Implementación de Protocolos de Trabajo, con la finalidad de evitar los errores significativos, y minimizar los errores aleatorios y sistemáticos.

\section{Práctica Actual del QA/QC}

Simon (2007), recopiló las propuestas de hasta siete consultores internacionales distintos, quienes coinciden en recomendar en promedio un $20 \%$ de muestras de control, entre blancos, duplicados, estándares y gemelos (Ver tabla 1).

\subsubsection{Modelamiento Geológico}

Un modelo geológico debe de ser sólido con todo el conjunto de datos geofísicos disponibles, los cuales proporcionan restricciones para la interpretación geológica y estructural de la zona de estudio. Entre uno de los softwares más conocidos es Leapfrog Geo Limited para el modelamiento geológico.

Entre otros Softwares de mayor demanda en la minería peruana encontramos el Datamine RM. Los entornos de estos programas nos permiten desarrollar la construcción de datos geológicos en 3D. Lo que años atrás, previos al 2000, se representaba de manera tediosa, ahora es más accesible la interpolación e interpretación de datos de un yacimiento (distribución de litologías y leyes de minerales).

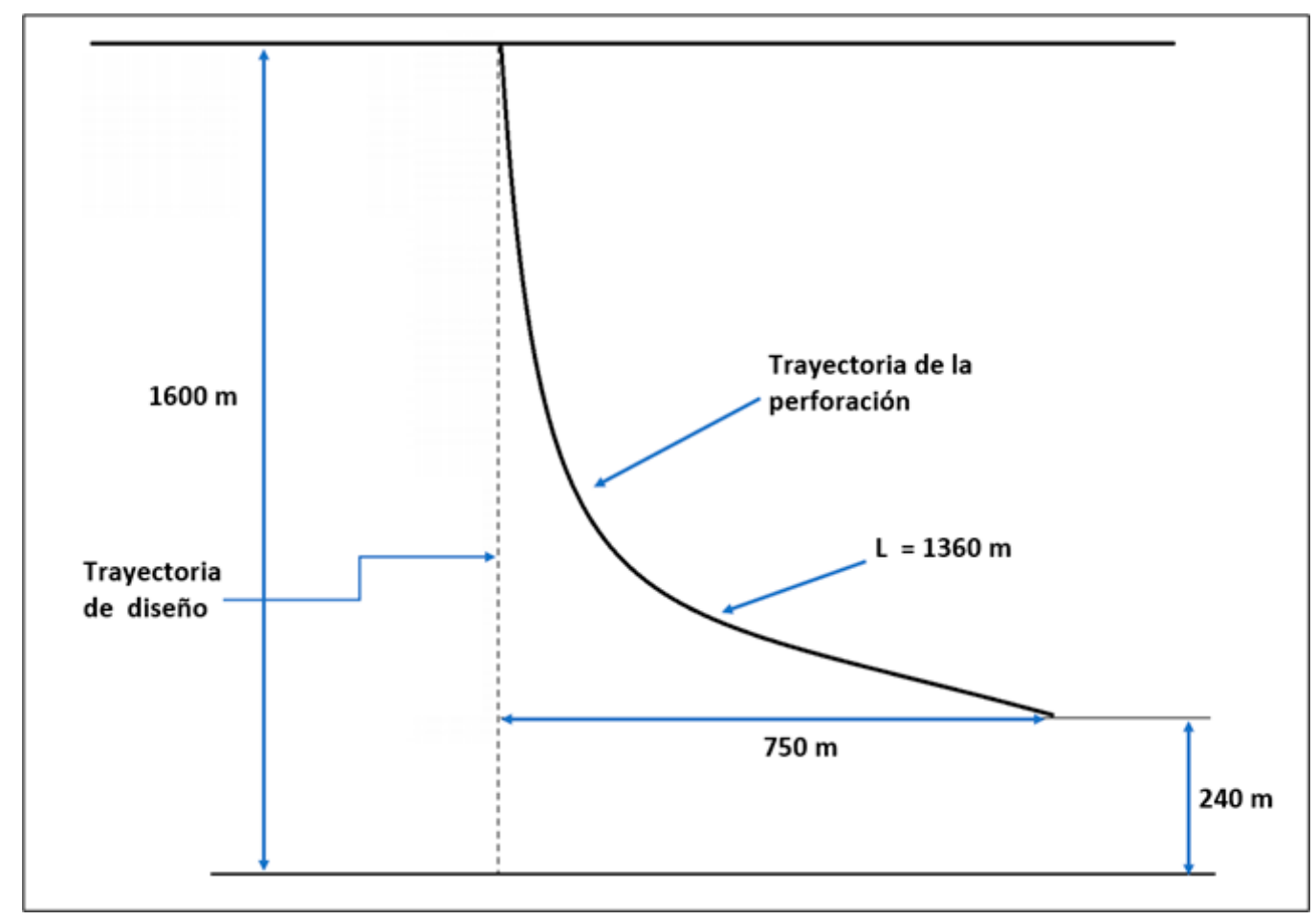

Figura 3. Pozo (Cambefort, 1968) 
Tabla 1. Proporciones actuales de muestras control (Simon, 2007)

\begin{tabular}{|c|c|c|}
\hline \multicolumn{3}{|c|}{ Proporción acostumbrada de muestras de control } \\
\hline Tipo de control & Frecuencia & $\%$ Adecuado \\
\hline Muestras gemelas (Duplicado de campo) & 1 de 30 a 50 & $2 \%$ \\
\hline Duplicados Gruesos & 1 de 30 a 50 & $2 \%$ \\
\hline Duplicados de Pulpa & 1 de 30 a 50 & $2 \%$ \\
\hline Estándar Bajo & \multirow{3}{*}{1 de 20 alternadamente } & $2 \%$ \\
\hline Estándar Medio & & $2 \%$ \\
\hline Estándar Alto & & $2 \%$ \\
\hline Blancos Gruesos & 1 de 30 a 50 & $2 \%$ \\
\hline Blancos Finos & 1 de 30 a 50 & $2 \%$ \\
\hline Duplicados Extensos & 1 de 20 & $2 \%$ \\
\hline
\end{tabular}

\subsubsection{Estimación de Recursos}

Muchas veces la complejidad y variabilidad de un yacimiento mineral dificulta determinar dominios geológicos homogéneos. De tal manera, que éstos sean utilizados para aplicar un control geológico a la estimación de recursos.

Los métodos geoestadísticos son usados ampliamente para la estimación y caracterización de los recursos minerales en los yacimientos. En la última década, se ha venido dando un gran desarrollo de la Geoestadística, de la mano con el avance de la tecnología digital, los cuales permiten su práctica a través de una amplia gama de programas profesionales (Datamine Studio RM, LeapFrog Edge, Isatis, Minesight, entre otros).

\subsection{Minería digital en los procesos mineros}

En el Perú la minería digital se encuentra en etapa inicial. Ya hay empresas que han puesto dentro de su plan estratégico el empleo innovaciones e implementación de tecnologías de la hoy llamada Cuarta Revolución Industrial -como es el caso de Anglo American y la compra de camiones autónomos para la mina Quellaveco-, pero otras empresas aún no consideran implementar estas tecnologías en un corto plazo.

Algunas de las tecnologías ya empleadas en Perú se detallan a continuación:

\subsubsection{Drones}

Los drones son vehículos aéreos no tripulados (VANT) que trabajan por control remoto.

Por su gran versatilidad, el uso de drones en minería y geología ha ido en aumento en los últimos años.

A continuación, mencionamos los usos más frecuentes de los Drones:

- Topografia: Se utilizan para realizar el levantamiento topográfico, pues permite generar el modelo digital del terreno DTM (Digital Terrain Model por sus siglas en inglés) a través del procesamiento de las imágenes captadas del terreno durante el vuelo.

- Control operacional: Los drones permiten realizar el monitoreo de las operaciones mineras a partir de una determinada área de observación(mirador) optimizando los tiempos de los supervisores de campo, pues se minimizan o eliminan los traslados entre diferentes niveles de la mina.

- Seguridad minera: En minería subterránea se emplean para verificar la seguridad de las cavidades generadas por los avances y desarrollo. De esta forma se evita que los trabajadores coloquen en riesgo su vida, exponiéndose a una caída de rocas o caída a un nivel diferente.

- Seguridad patrimonial: Por medio del monitoreo aéreo, el personal de seguridad patrimonial consigue controlar y mantener a salvo las propiedades mineras, evitando de esta manera posibles invasiones de mineros ilegales o robos al patrimonio.

- Prospección geofísica: Existen en el mercado Sensores aeromagnéticos que se pueden utilizar en la prospección geofísica.

- Hidrogeología: Existen en el mercado Sensores radio-magnetotelúricos para realizar estudios hidrogeológicos.

Medio ambiente: pueden utilizarse sensores químicos y atómicos para la detección atmosférica de gases y partículas radioactivas (Dominy et al., 2018).

\subsubsection{Despacho minero}

El despacho minero es el área que optimiza, gestiona y controla el movimiento de la flota minera (equipos de acarreo, carga y auxiliares de la mina).

En la actualidad existen diferentes empresas proveedoras de servicios de despacho minero. Entre las más conocidas podemos mencionar a Modular, Jig Saw, Mine Star, etc. 
Por medio de modernos sistemas de computación y comunicación, como por ejemplo los GPS de alta precisión, es posible gestionar indicadores como tiempos de traslado, tiempos de carguío, tiempos de descarga, tiempos muertos, tiempos en fila, etc.

El registro de estos eventos permite la toma de decisiones efectivas en el proceso productivo, incrementando la productividad, maximizando la utilización del tiempo y minimizando las perdidas. Todo esto en tiempo real.

\subsubsection{Seguridad minera}

El avance tecnológico también ha permitido minimizar los accidentes en las minas. En la actualidad se usan dispositivos de seguridad para detectar fatiga y somnolencia en los operadores y evitar de esta forma que se accidenten.

Estos dispositivos emiten una alerta cuando detectan que el operador está pestañeando o da señales de cansancio. De esta forma los supervisores pueden ordenar la paralización inmediata del equipo en un lugar seguro.

\subsubsection{Camiones autónomos}

Es una de las últimas tendencias tecnológicas en minería. Camiones autónomos o camiones operados a control remoto. Esta nueva tecnología viene siendo implementada en Perú por compañías que apuestan por una minería digital, como Anglo American que adquirió para su mina Quellaveco los camiones autónomos $777 \mathrm{G}$ de Caterpillar, con capacidad de $98.3 \mathrm{t}$.

Un estudio realizado por Southern Perú obtuvo como resultados que este tipo de sistema reduce en 78\% los accidentes de estos equipos, disminuye el requerimiento de volquetes, incrementa la productividad en $13 \%$ y baja el costo operativo en $5 \%$.

La automatización de equipos mineros está dentro de las implementaciones de la minería 4.0, siendo de gran importancia el análisis de Big Data, innovación en robótica, generación de algoritmos, y la inteligencia artificial.

Se cree que en 5 años la mayoría de los vehículos de la minería serán «inteligentes» y que las máquinas industriales serán automatizadas: cargadores, excavadoras, buldóceres, perforadoras y muchos más equipos serán automatizados. Además, se usarán robots de varios tipos para monitorear las operaciones de minería y así asegurarse de que todo se esté ejecutando de acuerdo con lo planificado.

\subsection{Minería digital en plantas de procesos metalúrgicos}

En la actualidad, el procesamiento de minerales se está volviendo más desafiante debido a que se están explotando minerales con leyes bajas, alta dureza, asociaciones complejas y el requerimiento de las gerencias de cada vez procesar más incluso sobrepasando las capacidades de diseño de una planta (Yahyaei, 2020). Es por lo que, el procesamiento de minerales ha estado ingresando a la revolución digital como un paso natural en la carrera para lograr procesos eficientes y optimizados.
Si bien en el Perú ya se vienen aplicando tecnologías basadas en machine learning para el reconocimiento de imágenes (Split Online ${ }^{\circledR}$, JKFrothCam ${ }^{\circledR}$ y aplicaciones de Ore Sorting), sistemas de control avanzado (Sistemas expertos y controles predictivos por modelo MPC), aplicaciones de Bigdata y analytics, aún existen herramientas como la robótica, sistemas inteligentes para la toma de decisión y aplicaciones IoT (Internet of Things) que podrían lograr el objetivo final de esta revolución, lo que nos conducirá a que las plantas sean autónomas.

Una práctica actual es centralizar todos los datos de producción y gestión de las distintas áreas de la unidad minera en una plataforma ERP (como SAP ERP®) o ABB Ellipse $\left.{ }^{\circledR}\right)$, pero en la minería del futuro es de esperar que también se incluyan datos de operación en tiempo real y la histórica dando un acceso total y transversal al personal que se encargará de liderar estas operaciones.

Uno de los objetivos de la industria 4.0 y que ya fueron logrados por otras industrias como la automotriz y la electrónica, es la de operar fábricas o líneas de montaje de manera autónoma, es decir, sin intervención humana. El introducir autonomía al procesamiento de minerales ofrece muchas ventajas, entre las que se pueden destacar: mayor seguridad en la operación y mayor productividad ya que las actividades de menor complejidad serán automatizadas $\mathrm{y}$, por lo tanto, los ingenieros se podrán enfocar más a trabajos de planificación y optimización (Australian Mining, 2019).

A continuación, se revisará cómo se viene aplicando las tecnologías dispuestas por la Industria 4.0 a los procesos metalúrgicos y el futuro de los sistemas de control.

\section{artificial}

\subsubsection{Data analytics, machine learning e inteligencia}

Según McCoy \& Auret (2019) las aplicaciones de Data analytics y machine learning en el procesamiento de minerales se agrupan en tres grandes grupos:

- Modelamiento basado en datos, consiste en la aplicación de técnicas de aprendizaje supervisado tales como regresión de mínimos cuadrados (PLS), regresión de componentes principales (PCR) y redes neuronales (RNA) con el objetivo de generar modelos multivariantes y sensores virtuales (soft-sensors) a partir de data histórica. Usualmente las variables a modelar son las que por su naturaleza son difíciles de medir por un instrumento o una para respaldar una señal de campo (\%llenado del molino, \%carga circulante, P80, etc.) o estados de un equipo (probabilidad a falla de molino, de una bomba o roping de un hidrociclón) (ver Figura 4).

Carrión

- Diagnóstico y detección de fallas, basado principalmente en técnicas de agrupamiento o clustering tales como Análisis de componentes principales (PCA) y variantes no-lineales de PCA. La aplicación consiste en colectar la data histórica de cuando el equipo se encuentra en 
operación estable o en el estado que deseamos modelar y, generar un modelo PCA con esa data. Luego el modelo PCA se lo implementa en el DCS y cuando observemos valores fuera del clúster que generamos con las condiciones estables, se puede deducir que es provocado por un comportamiento anómalo o mal funcionamiento (ver Figura 5).

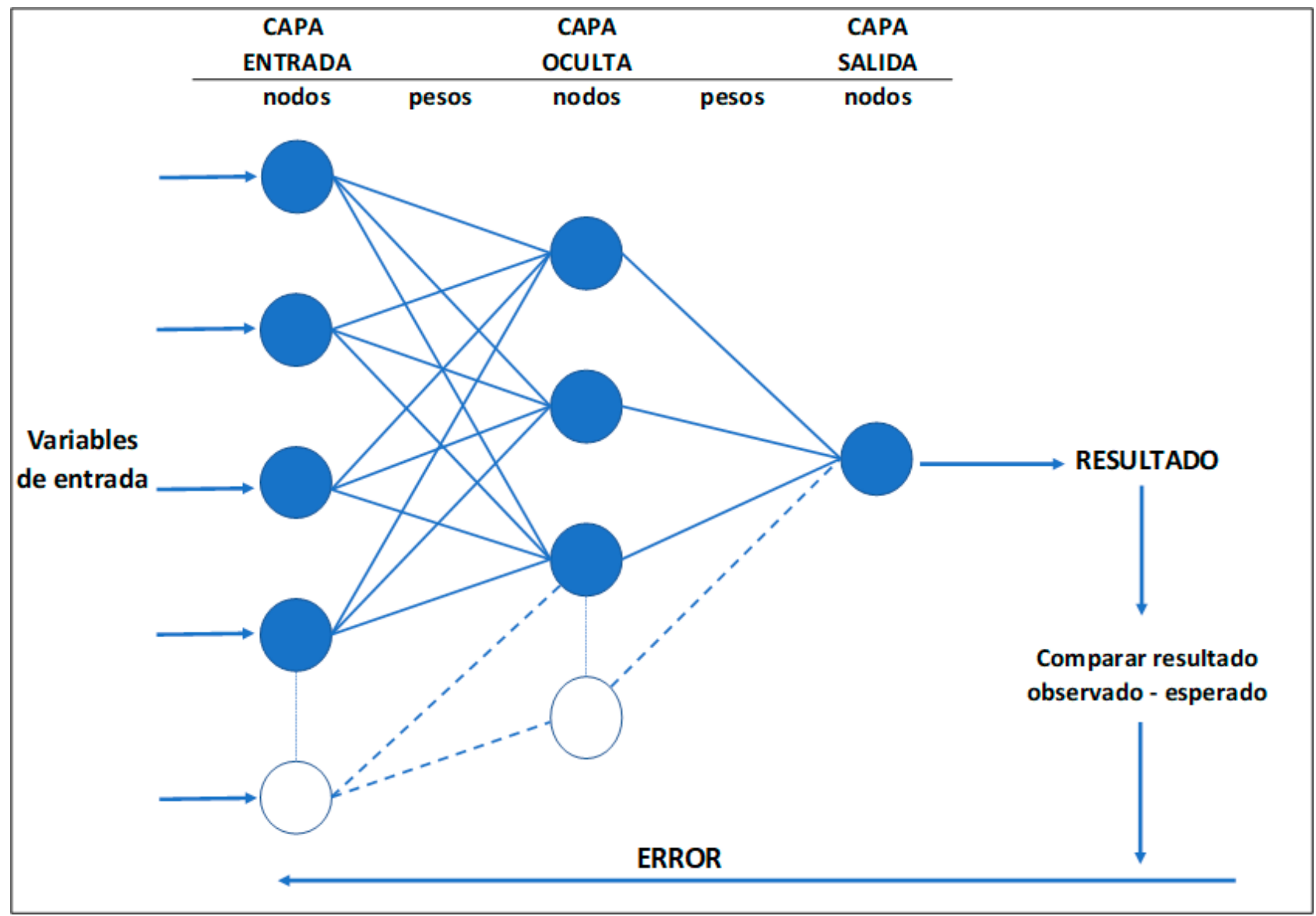

Figura 4. Niveles o capas de una RNA(Carrión Osnayo, 2018)

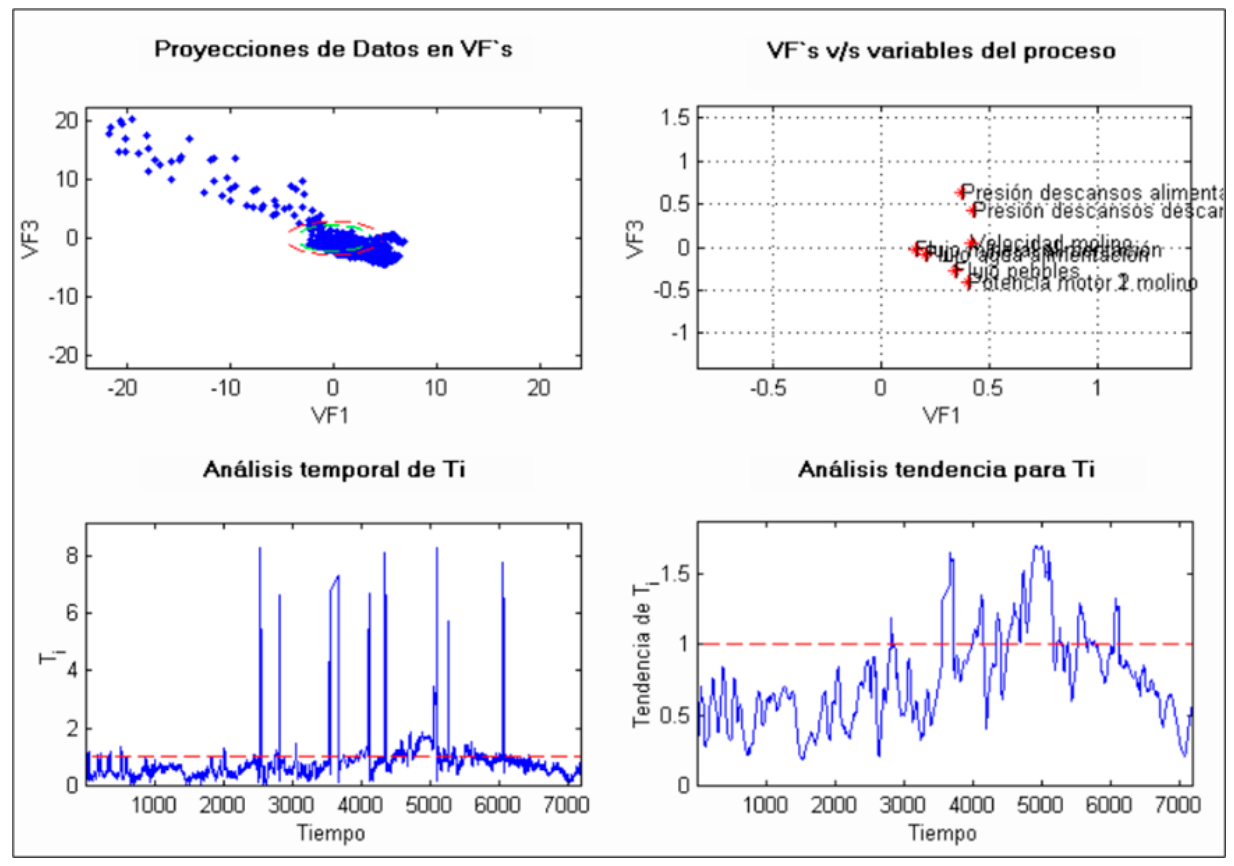

Figura 5. Seguimiento de perturbaciones en el molino SAG 1 (Romero et al., 2006) 
- Técnicas de machine visión, basado en el análisis de imágenes o videos mediante técnicas de procesamiento de imágenes. Si bien estas técnicas han sido usadas tradicionalmente en el análisis en tiempo real de imágenes para estimar la distribución granulométrica de una faja o el grado de la espuma en una celda de flotación, su uso también está implementado en la tecnología Ore Sorting. Hay varias experiencias de éxito en Ore Sorting en el Perú, en principio el Ore Sorting explota las diferencias físicas (color, tamaño, densidad), propiedades magnéticas y propiedades atómicas que existen entre la mena de interés y la ganga para separarlos antes de que ingresen a la planta de procesamiento (Guthrie, 2019) (ver Figura 6).

3.3.2. Sistemas de control avanzado y plantas autónomas

Es común que una planta de procesamiento de mediana a gran magnitud cuente con un sistema de control robusto con el objetivo de estabilizar y optimizar el proceso. Pero en el contexto de Minería digital la jerarquía control que todos conocemos es distinta, y se puede clasificar en cinco niveles (Australian Mining, 2019) (ver Figura 7).

Alimentación de la

\section{Sensor o combinación de sensores}

planta o transportador móvil en el pozo (cinta transportadora completamente cargada $3600 \mathrm{tph}, 5 \mathrm{~m} / \mathrm{s}$ )

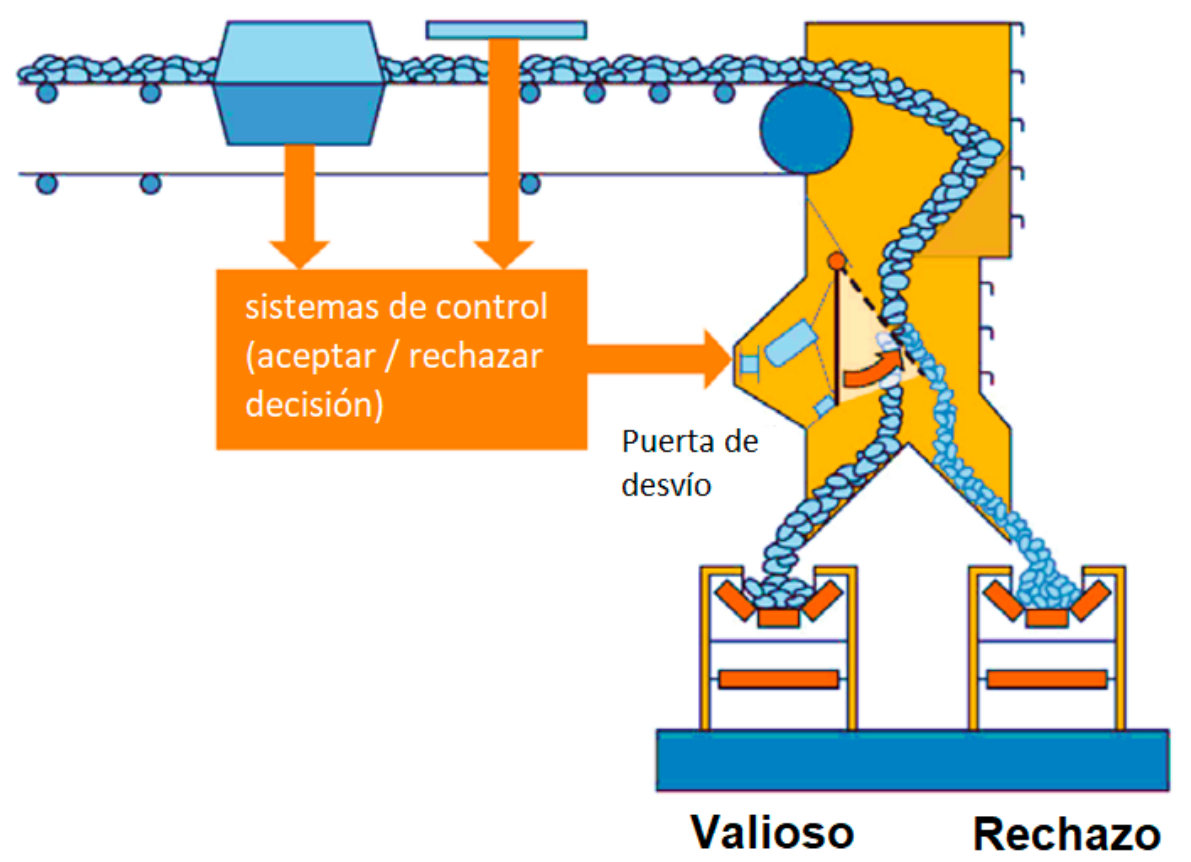

Figura 6. Mecanismos de funcionamiento en Ore Sorting (Guthrie, 2019).

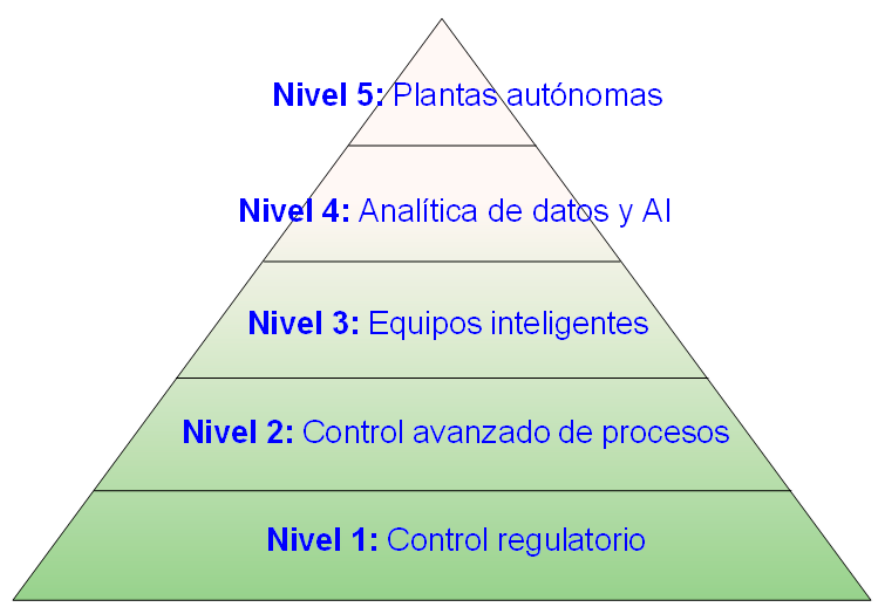

Figura 7. Niveles para lograr la autonomía de una planta (Australian Mining, 2019) 
Nivel 1, se refiere a la instrumentación básica de campo, controladores, lazos de control donde el operador es que ingresa el set-point y la variabilidad del proceso depende de la capacidad de reacción del operador.

Nivel 2, se tienen los sistemas de control avanzado tales como Sistemas Experto o MPC en los cuales el software es el que busca el punto óptimo y de forma automática modifica el set-point para compensar las perturbaciones.

Nivel 3, la mayoría de las tareas del operador han sido automatizadas, y las perturbaciones menores son corregidas por equipos y actuadores inteligentes.

Nivel 4, adopta las soluciones explicadas anteriormente para la detección de anticipada de fallas y el mantenimiento predictivo y, junto a aplicaciones de Inteligencia Artificial es posible que la IA asesore al operador sobre los puntos óptimos de trabajo los cuales son ignorados por el sistema de control avanzado.

Nivel 5, el control avanzado de procesos se ha incrementado aún más con sensores y analizadores adicionales. El operador es altamente capacitado y es compatible con IA, además se cuenta con un simulador de proceso dinámico en tiempo real (Digital Twin). El mantenimiento es $100 \%$ predictivo y preventivo, y se deberían eliminar las paradas imprevistas.

El ingeniero geometalurgista del futuro, además de dominar su especialidad, también deberá tener conocimientos de las aplicaciones de machine-learning y automatizaciones aplicadas a la planta de beneficio, debido a que todos los esfuerzos de los geólogos, geometalurgia y mineros, si fueron realizados de manera correcta se reflejarán en el proceso de recuperación del metal de interés.

Si bien en la actualidad ya existen tecnologías que dan autonomía a los camiones mineros, hablar de plantas de procesos autónomas aún está un poco lejano, pero debido a los acontecimientos actuales es de esperar que los principales proveedores y empresas de ingeniería ya estén acelerando el desarrollo de la tecnología necesaria para lograr la transformación digital de las plantas de procesos.

\subsection{Geometalurgia digital en el Perú}

La geometalurgia como herramienta, se aplica desde los años 1998 a 2002, en las minas grandes de cobre como una necesidad operacional y también por el desarrollo de softwares con cálculos a nivel de bloques, junto con la aplicación de nuevas tecnologías como Qemscan, ICP, SMC, SPI; ya que para los nuevos proyectos las Normas JORC, 43,-101 exigen mayor confianza.

A inicios de los años 2000 se desarrollaron pruebas de flotación aplicando un esquema de regresión lineal, basado en la microscopía óptica hasta llegar al grado de liberación, esta se convirtió en una herramienta de apoyo entre la geología y la metalurgia, generando el nuevo concepto de Geometalurgia (Manzaneda Cabala, 2010).

Otro caso es el de la Unidad Minera Atacocha que, a partir del año 2004, sus resultados indicaron una mejor recuperación general de cobre, debido a que la planta de flotación logró optimizar su proceso mediante microscopia óptica observando los amarres y logrando la molienda aceptable hasta lograr su grado de liberación y sugerir la remolienda del bulk. Por lo tanto, se logró un concentrado de cobre con menos de $10 \%$ de plomo (Cánepa Iannacone \& Manzaneda Cabala, 2005).

Con la aplicación del microscopio electrónico ayudo a resolver problemas como el caso de la alabandita el cual presenta propiedades ópticas similares a la esfalerita, un sulfuro muy dañino en la flotación. La única manera de diferenciar es con la aplicación de microscopia electrónica de barrido (MEB), el cual identifica esfalerita rica en manganeso y mangano calcita, con esta información los departamentos de geología y planta toman sus previsiones.

Otro caso, es el de la mina Cerro Lindo ( $\mathrm{Pb}-\mathrm{Cu}-$

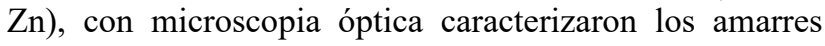
mineralógicos en el concentrado de cobre (de mala calidad por el contenido de $\mathrm{Pb}$ ), en donde se recomendó la remolienda generando concentrados de $\mathrm{Cu}$ y concentrados de plomo de buena calidad (Meza \& Núñez, 2018).

En la actualidad las operaciones mineras, en especial, la mediana y gran minería consideran a la geometalurgia como un complemento necesario en la viabilidad del proyecto.

En la geometalurgia es importante las nuevas tecnologías cada una con sus fortalezas y debilidades, pero todas son complementarias.

\subsection{Geometalurgia digital en minera Goldfields La Cima}

Cerro corona es un yacimiento tipo pórfido $\mathrm{Cu}-\mathrm{Au}$, ubicado en el distrito minero de Hualgayoc, región de Cajamarca a 3800 m.s.n.m. en el norte del Perú.

El pórfido tiene como rocas hospedantes a calizas de la Formación Jumasha. El contacto intrusivo caliza generó una zona de Skarn de aproximadamente 20 metros de ancho con mineralización de $\mathrm{Pb}-\mathrm{Zn}$.

El yacimiento inició sus operaciones en el año 2008, conteniendo recursos estimados de $3.05 \mathrm{Moz}$ de oro a 0.81 $\mathrm{g} / \mathrm{t}$ y $108 \mathrm{Mt}$ de cobre a $0.42 \%$ y reservas de $1.75 \mathrm{Moz}$ con $0.9 \mathrm{~g} / \mathrm{t}$ de oro y $60.5 \mathrm{Mt}$ de cobre con $0.47 \%$.

A partir del año 2011, se realizaron perforaciones (15 $000 \mathrm{~m}$ ) de relleno sobre el área del pórfido considerando los niveles de alteración. Los sondajes se realizaron, considerando el objetivo de determinar unidades geometalúrgicas que tenían como base la descripción geológica y los resultados geoquímicos.

Con las unidades geometalúrgicas, se logró identificar las zonas o áreas con características similares que ayudaban a mejorar la recuperación de los valores de oro y cobre en la mina. Aquello permitió, a su vez, mejorar los ingresos económicos de la operación minera, para que pueda ser distribuido en beneficio de sus accionistas y de la repartición de impuestos y regalías derivados, así como el beneficio a las comunidades aledañas. 
La mena de $\mathrm{Cu}$, en mayor proporción, es la calcopirita; en menor proporción es la bornita, covelita y calcocita. El oro se encuentra en forma nativa y en menor proporción en forma de electrum.

En el año 2013, se realizaron estudios de caracterización mineralógica con el apoyo del análisis Qemscan. Con la finalidad de determinar la mineralogía modal, así como el tamaño de los granos, las asociaciones y la liberación de los minerales de interés y su relación con las partículas de oro. Los estudios identificaron pirita común y pirita amorfa, el oro se encuentra encapsulado en la pirita amorfa y en menor grado en la calcopirita. Además, se dio a conocer que la mineralogía varía de acuerdo con el tipo de alteración, por lo cual se recomienda una molienda más fina. En la actualidad, el proceso que realizan es la flotación, gravimetría y remolienda (Baumgartner et al., 2016).

Debido a la complejidad y variabilidad del Mineral en Goldfields, ha sido constante la búsqueda de sistemas de análisis y métodos, tanto para geometalurgia y control de procesos. En cuanto a la automatización, se ha adoptado los sistemas expertos en el área de Molienda y flotación, el cual permite un mejor control de la operación.

\subsection{Geometalurgia digital en minera Las Bambas}

Si bien el concentrador Las Bambas en un inicio ya contaba con un nivel de automatización propio de plantas modernas, es que en los primeros años se implementaron muchas herramientas para mejorar el control de la planta, entre los que se puede destacar: analizadores de tamaño de partículas en fajas transportadoras, medidor de impactos críticos en molienda, detector de acordonamiento de los hidrociclones, sistemas de control experto para molienda, analizador de leyes en flotación, entre otros.

Además, es que previo al inicio de operaciones del concentrador (2014) se ejecutó un plan geometalúrgico con el objetivo de caracterizar el mineral que ingresará a la planta concentradora por los tres primeros años de explotación. El depósito que se estudió fue el tajo Ferrobamba, el cual está compuesto por $53 \%$ pórfido, $40 \%$ skarn y $7 \%$ otros. Para fines geometalúrgicos se definieron 6 UGMs, dos para el pórfido, dos para skarn zona óxidos y dos para el skarn zona sulfuros,

El objetivo del programa de pruebas metalúrgicas fue caracterizar las UGMs, estudiar su variabilidad y poder determinar, entre otros objetivos el consumo específico de energía, el comportamiento abrasivo, el efecto del P80 a flotación, el efecto del \% de sólidos en flotación rougher, grado de remolienda de los concentrados primarios, entre otros. Para luego mediante simulaciones y modelamiento determinar la capacidad a tratar por cada UGM, cuantificar la adición de reactivos en molienda teniendo como objetivo minimizar el efecto de las arcillas y minerales de hierro, entre los que se destacan.

Los softwares que fueron usados para las simulaciones fueron JKSimmet ${ }^{\circledR}$ para analizar la capacidad de tratamiento en molienda SAG/Bolas y la interacción del T80 y P80 en el circuito; y el software IGS (SGS) para las simulaciones de molienda - flotación con el objetivo de establecer recuperaciones y grados de concentrados.

Los resultados las pruebas de conminución para el tajo Ferrobamba lograron caracterizar exitosamente comportamiento frente a las operaciones de conminución, resultando un modelo de tonelaje tratado robusto. De las pruebas de flotación, se determinó una función lineal para la recuperación de cobre en función de la ratio $\mathrm{CuOx} / \mathrm{CuT}$, además definir el impacto de un P80 a flotación de 240 a 300 micras y cómo este impacta a la recuperación de cobre.

\subsection{Geometalurgia digital en minera en Complejo Pasco}

Actualmente Nexa Resources lleva implementando la geometalurgia en sus 3 Unidades en Operación, el cual reside U.M. Cerro Lindo, U.M. El Porvenir y U.M. Atacocha, los dos últimos pertenecientes al llamado Complejo Pasco. Los esfuerzos están direccionados en el Complejo Pasco, ya que se tienen problemas en la recuperación de zinc. Por la presencia de minerales de manganeso en este caso con el sulfuro de manganeso; como también esto ayudará a que se puedan reducir costos en molienda y en flotación.

En el Complejo Pasco, se evidencian distintos tipos de mineralización, siendo las del tipo skarn las más extendidas, mineralización asociada a brechas tectónicas, mineralización asociada a un sistema epitermal de intermedia sulfuración y mineralización asociada a un sistema tipo pórfido.

El proceso productivo de ambas unidades es por flotación de mineral en planta concentradora.

Para la optimización de sus actividades mineras, se culminaron los trabajos de preparación y desarrollo asociados a la integración subterránea entre las unidades mineras El Porvenir y Atacocha. Posteriormente, el siguiente escalón es el proceso de integración operacional de las unidades mineras mencionadas, con la finalidad de unificar operaciones y lograr sinergias en la producción de concentrados de zinc, cobre y plomo con contenidos de oro y plata.

Por lo cual, se propuso un estudio geometalúrgico el cual presenta los siguientes criterios a analizar en las 3 áreas importantes que abarcan la cadena de valor: Geología (génesis, mineralización, eventos y alteraciones), Planeamiento (criterio para optimización y planificación de producción) y metalurgia (tonelaje, recuperación ley de concentrados, costos operativos y blending).

Con la aplicación de la geometalurgia se tuvo los siguientes objetivos principales:

- Maximizar el valor del depósito

- Asegurar el tonelaje como fue estimado.

- Reducir riesgos en la predicción económica.

- Minimizar problemas con el blending.

- Mejorarla comunicación entre mineros, geólogos y metalurgistas. 
- Documentar dominios y parámetros geometalúrgicos.

Para el desarrollo de este estudio, se consideraron diversas herramientas de análisis como el uso de softwares recientes en esta era digital, como es el caso novedoso del software geometalúrgico "Cancha".

A continuación, se detallan las herramientas y softwares de análisis y visualización utilizados.

\section{Herramientas de análisis}

- Box plot

- Función Acumulativa de distribución

- Diagramas ternarios

- Matrices de correlaciones de Pearson

\section{Software}

- Orange

- ioGAS
- Minitab

- Strater

- Geoscience Analyst

- GVMapper

- Cancha

\section{- Software geometalúrgico: "CANCHA"}

La unidad minera el Porvenir se encuentra trabajando con el software "Cancha", cuya fortaleza es realizar una selección de muestras más rápida a partir de data de sondajes existentes como también de nuevos Sondajes, clasificándolo como por ejemplo para un muestreo de sondajes para conminución y flotación; nos ayuda en que podemos definir de que metro a que metro sirve para conminución o para flotación desde una Pc (ver Figura 8).

También ayuda bastante en análisis de datos estadísticos, teniendo como resultado graficas estadísticas (ver Figura 9).

\section{Drill log viewer}

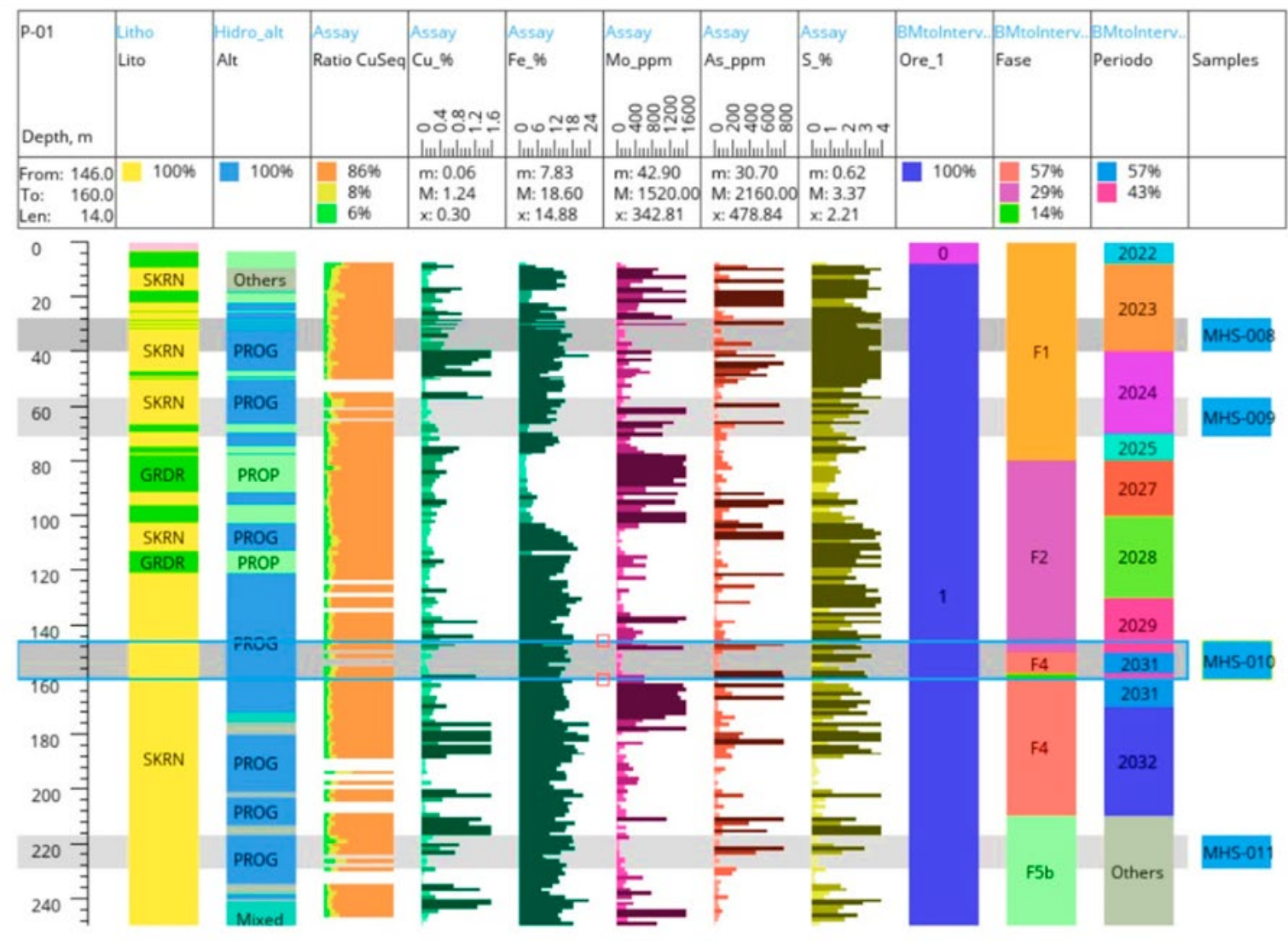

Figura 8. Visor de registro de perforación (Fuente: Transmin MC, 2020) 


\section{- Software Geológico: “GVMapper”}

Los beneficios del GVMapper es que integra en una misma base de datos la información de sondajes, de cartografía de terreno y de interpretación de plantas y perfiles (ver Figura 10).

- Posee un esquema de datos que permite completa adaptabilidad a cualquier proyecto.
- $\quad$ Es un software de captura digital de datos.

- $\quad$ Puede utilizarse en terreno.

- No requiere conexión permanente a red para funcionar.

- Posee una alta capacidad de interacción con los formatos y aplicaciones más usadas en la industria (GIS, Modeladores y Bases de datos).

\section{Histogram and distribution curves}
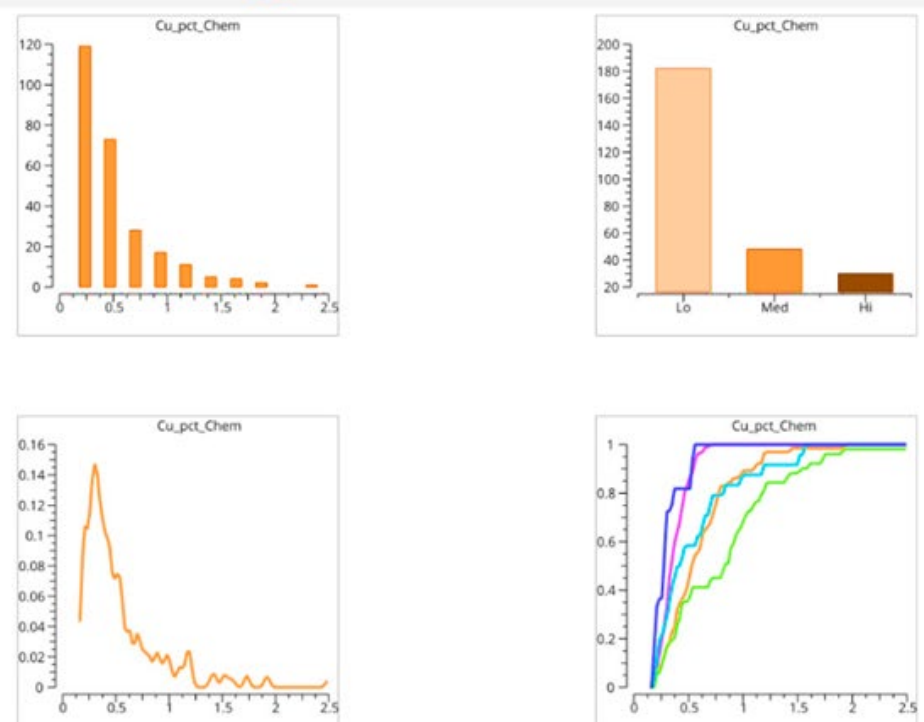

Figura 9. Gráficas estadísticas en el Software Geometalúrgico Cancha (Fuente: Transmin MC, 2020)

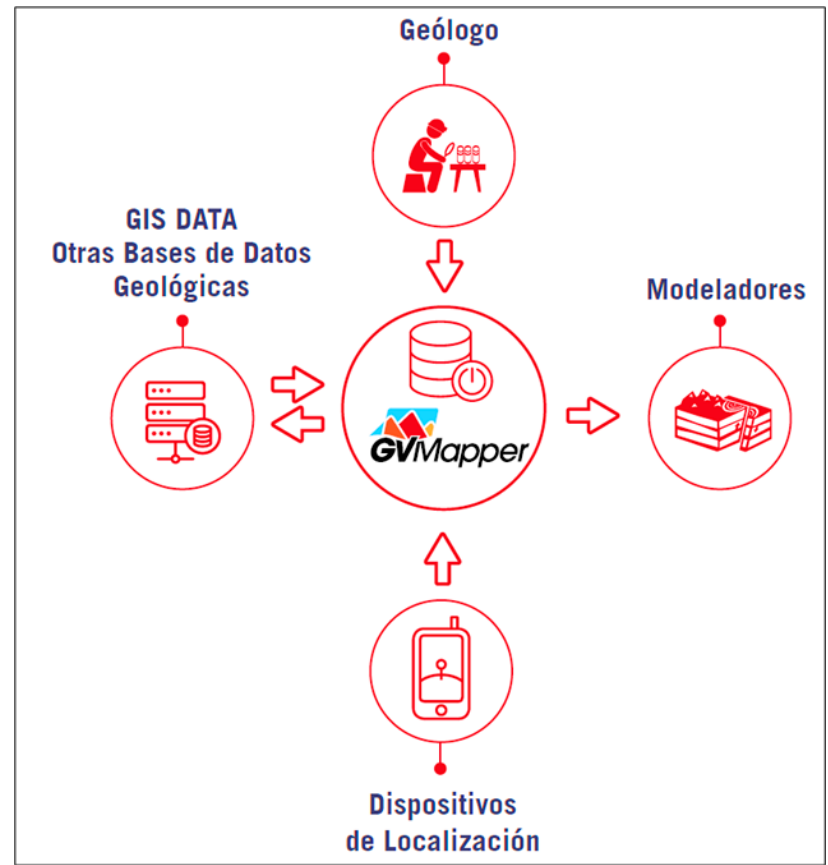

Figura 10. GvMapper y su conectividad con otros sistemas (Fuente: GVMapper, 2020) 


\section{Captura digital con el software GVMapper}

La captura digital es la instancia en que se ingresa un dato desde su fuente original y en el mismo lugar de origen, directamente a una base de datos de forma validada y sin intervención de terceros (ver Figura 11).

\section{Ventajas con el software GVMapper:}

- Validación de datos in situ.

- Captura completa de las observaciones.

- Aumento de rendimiento respecto. Centralizando de la información.
- No hay transcripción o digitalización.

- Información histórica fácil de acceder.

- Incorporación de datos adicionales del lugar de la captura.

\section{Logueo de sondajes con el software GVMapper:}

- Sencilla e intuitiva interfaz de logueo (ver Figura 12).

- Despliegue dinámico de leyes, geotecnia y geología.

- Integra la fotografía digital referenciada del testigo.

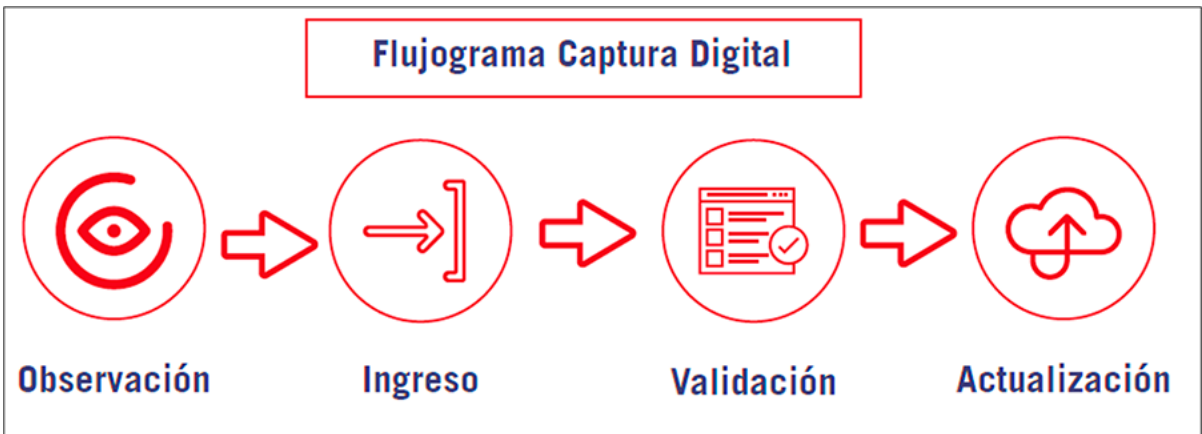

Figura 11. Flujograma Captura digital (Fuente: GVMapper, 2020)

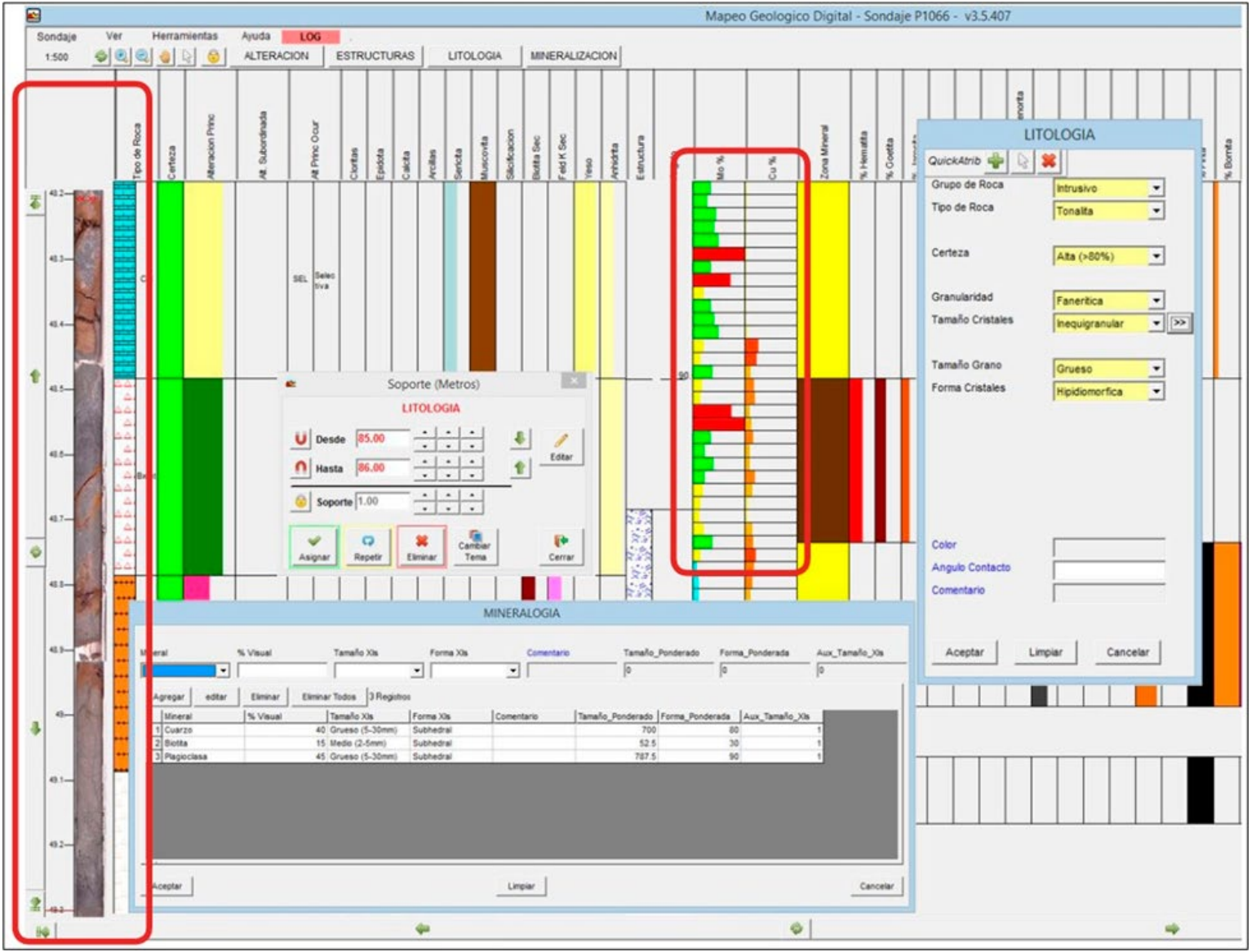

Figura 12. Interfaz de Usuario - Logueo de Sondajes. (Fuente: GVMapper, 2020) 


\section{Mapeo de Superficie con el software GVMapper}

- Atributación directa a base de datos exportable y/o conectable a GIS.

- Utilización de elementos de apoyo (imágenes, topografía, datos territoriales, propiedad minera, etc.)

- Conexión directa a GPS, para ubicación y captura de puntos (ver Figura 13).

\section{Interpretación de perfiles con el software GVMapper}

- Sencilla interfaz para caracterizar cuerpos, identificar anomalías y complementar el modelo geológico.

A tributación directa a base de datos y polígonos
exportables a modeladores y GIS (ver Figura 14).

Visualización simultánea con el software GVMapper:

- Despliegue simultáneo de múltiples mapas, plantas y perfiles (ver Figura 15).

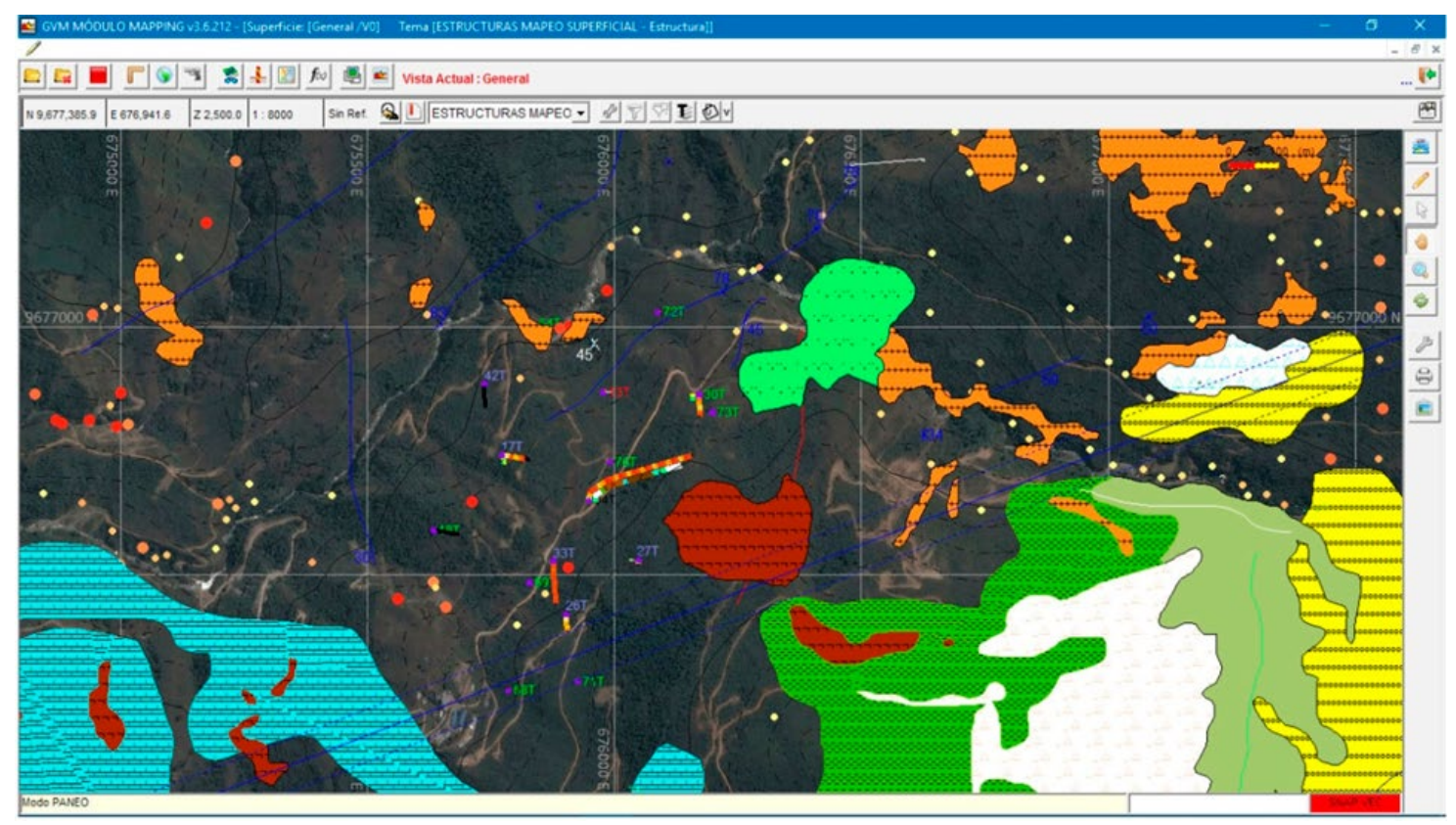

Figura 13. Interfaz de Usuario - Mapeo de superficie. (Fuente: GVMapper, 2020)

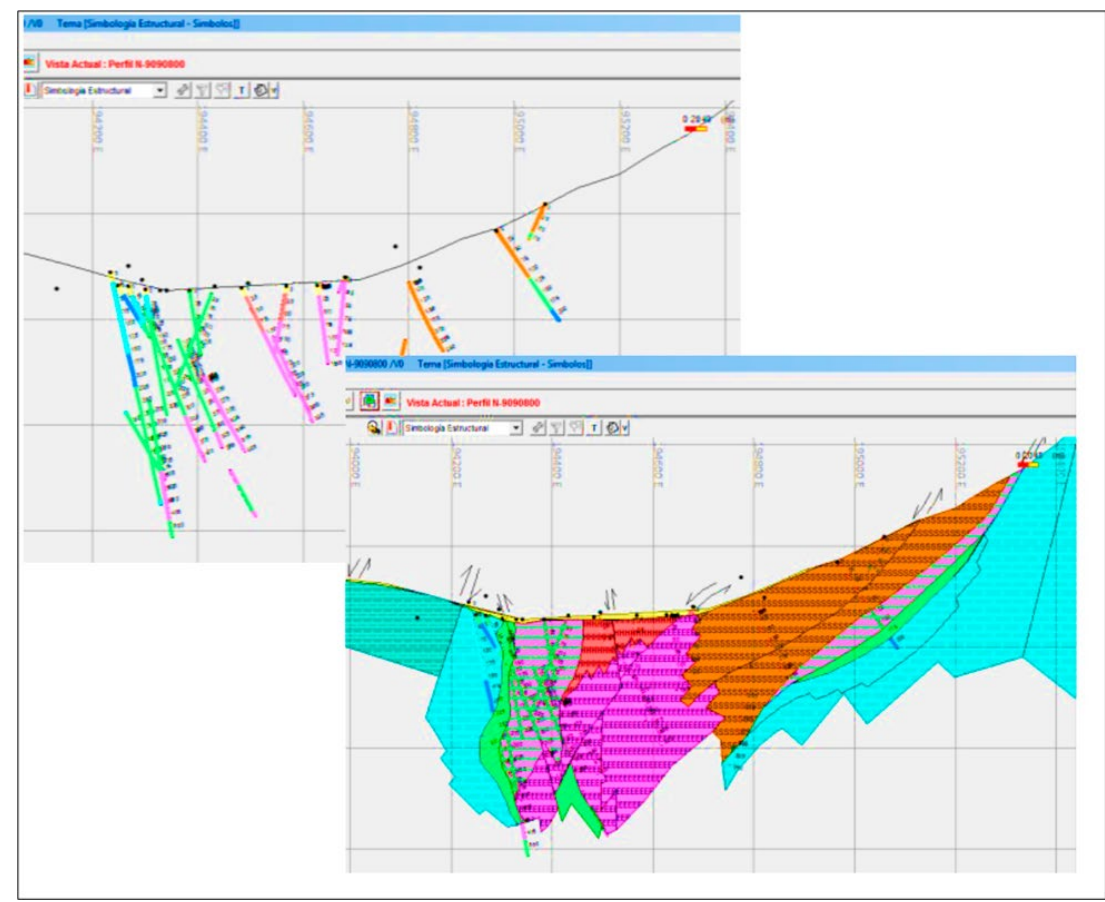

Figura 14. Interfaz de Usuario - Interpretación de perfiles. (Fuente: GVMapper, 2020) 


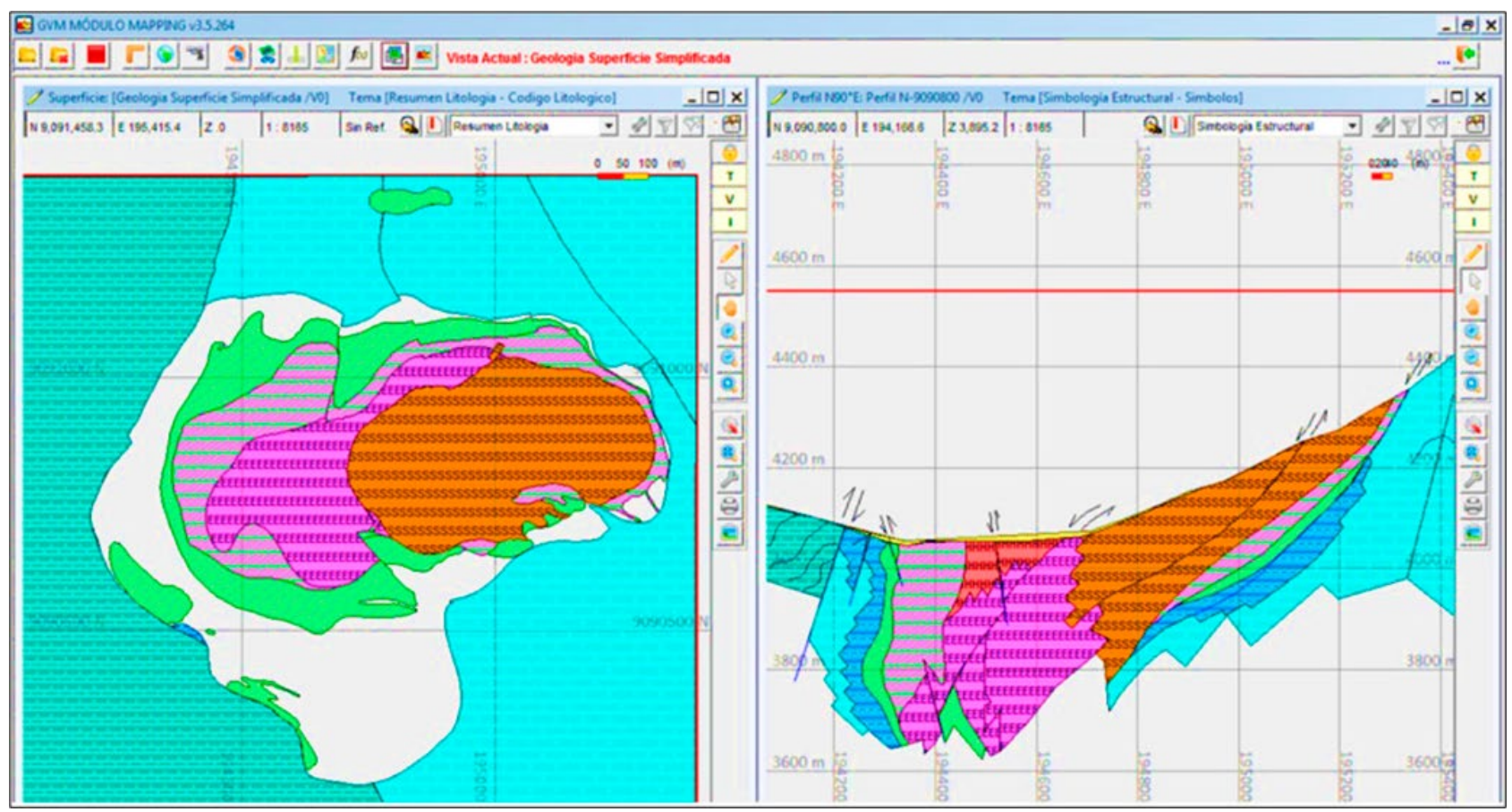

Figura 15. Interfaz de Usuario - Visualización GVMapper. (Fuente: GVMapper, 2020)

Este estudio geometalúrgico se basó en el modelamiento del tonelaje, OPEX, recuperaciones finales y la calidad del concentrado. Para la evaluación de estos modelos geometalúrgicos, se aplicó la evaluación del índice de abrasión (Ai), la dureza, el índice de Bond (BBWi), las recuperaciones de $\mathrm{Pb}, \mathrm{Zn}$ y $\mathrm{Cu}$; recuperaciones de los contaminantes As y Mn.

Además, para la generación de los dominios geometalúrgicos en el modelo de bloques, se analizó que fue necesario la implementación del cuerpo mineralizado en BM open Pit, la mineralización (Sulfuros Mn y $\mathrm{Pb} \mathrm{As}$ ) y leyes de manganeso y arsénico.

En conclusión, a través del estudio geometalúrgico, se identificaron los siguientes riesgos:

- El tonelaje de planta, el cual puede ser afectado por mineral duro en el cuerpo mineralizado, en veta Carmen Norte 3 y Open Pit.

- La recuperación de los minerales valiosos, en el caso particular de la recuperación de $\mathrm{Zn}$, que disminuye por el incremento de la ratio $\mathrm{Pb} / \mathrm{Zn}$ en la cabeza.

- La calidad de concentrado, el cual puede verse afectado por los siguientes minerales:

- Presencia de Mn en el concentrado de Zn, posiblemente relacionado a inclusiones de $\mathrm{Mn}$ en la matriz de Esfalerita y presencia de alabandita

- Presencia de As en el concentrado de Zn, relacionado a la presencia de arsenopirita.

- Presencia de As en el concentrado de Pb, relacionado a la presencia de $\mathrm{Pb}$ y As.

\section{DISCUSIÓN}

La propuesta de una minería digital abre un bagaje de tecnologías que es probable hace años no estaban consideradas como necesarias para la operación; como lo son los camiones autónomos, uso de drones o sistemas basados en machine learning, $\mathrm{Y}$ es de esperar que, en los años venideros, todo esto sea considerado desde la etapa de diseño de una operación, ya que otorgan a la operación herramientas que optimizan y otorgan una independencia parcial a la operación.

Existen tecnologías y desarrollos como los mencionadas en este artículo, que resuelven necesidades específicas y que tienen las distintas áreas del negocio minero, pero aún hay herramientas de la Industria 4.0 como la robótica, que es muy usada en la industria de manufactura de autos y ensamble de equipos electrónicos, que aún no tienen acogida en la industria minera y esto respondería al comportamiento de los empresarios mineros en invertir por tecnologías que tienen cierto éxito comprobado impidiendo hasta cierto grado el experimentar con nuevas alternativas de tratamiento o equipos que rompan el paradigma.

La crisis epidémica, en un mundo tan cambiante, nos hace ver los vacíos en la tecnología digital de la industria minera, valorar los avances y encontrar otras oportunidades de mejora de manera urgente, para que se pueda seguir desarrollando trabajos de modo remoto. Esta forma de trabajo se ha establecido significativamente en muchas empresas mineras, sea el caso de Antamina y Las Bambas. Resaltando la importancia de tener la conexión y comunicación de redes digitales de sistemas y equipos de forma íntegra.

La implementación de la Geometalurgia en las operaciones mineras ha traído buenos resultados en especial 
para la grande y mediana minería. En la pequeña minería y minería artesanal la implementación de esta disciplina no se realiza porque lo ven muy costoso y necesitan capacitación.

La pequeña minería y la minería artesanal ante este panorama deben mejorar la calidad de sus productos por lo cual se hace necesario la implementación de algunos estudios técnicos como: la caracterización mineralógica y la implementación de la tecnología Ore Sorting, la combinación de ambos puede generar un pre-concentrado de buena calidad, lo cual le generaría mayor rentabilidad.

La implementación de tecnologías ayuda a optimizar procesos, reducir costos y generar valor al proyecto. Estas implementaciones están en fase inicial en el Perú, a diferencia de otros países tradicionalmente mineros como USA, Canadá y Australia. Afortunadamente las empresas mineras, ya comienzan a considerar en sus planes estratégicos a la Minería Digita 4.0, y se espera que en los próximos 5 años tengamos una minería más digital y tecnológica. De momento ya llegaron al Perú softwares que nos ayudan en los trabajos de control de operaciones, modelamiento geológico, planeamiento de minas, voladuras electrónicas controladas, levantamiento topográfico por drones, análisis de minerales, y recientemente la utilización de camiones autónomos, por nombrar algunas tecnologías.

\section{CONCLUSIONES}

- Es un reto importante que la minería en nuestro país se inserte de forma íntegra en la automatización y digitalización en todos los procesos de la industria minera, a través de la geometalurgia, que abarca desde la exploración hasta la operación. De tal manera, que estas innovaciones incidan significativamente en la productividad, seguridad y la capacidad de procesamiento de la información, para resolución de problemas con decisiones más acertadas, que brinden valor económico al negocio minero.

- Si bien las empresas mineras sobre todo las medianas y grandes están realizando denotados esfuerzos para optimizar y automatizar sus operaciones mineras, aún queda un largo camino en la digitalización de la minería, pero debido a los tiempos que estamos afrontando es de esperar que los esfuerzos para automatizar y minimizar la interacción humano-máquina tengan un crecimiento exponencial.

- La digitalización de la geometalurgia, como la hemos tratado en este artículo, no solo se centra en la concepción del modelo geometalúrgico. La geometalurgia es una interdisciplina que tiene como objetivo que el profesional cuente con un entendimiento de todo el ciclo del negocio minero.

\section{AGRADECIMIENTOS}

En primer lugar, agradecemos a Dios por la vida y bendecirnos cada día. También hacemos extensivo nuestro agradecimiento a la Unidad de Posgrado de la Universidad Nacional Mayor de San Marcos, por el espacio para nuestro desarrollo académico en esta ciencia como es la Geometalurgia. A los docentes de la unidad de posgrado, por sus recomendaciones y por impulsarnos a seguir una mejora continua en la investigación.

\section{REFERENCIAS}

Australian Mining. (2019). Metso's roadmap to autonomous processing: Jani Puroranta. https://www.australianmining. com.au/features/metsos-roadmap-to-autonomousprocessing/

Baumgartner, R., Escobar, G., Gomez, P., Uzategui, A., \& Nuñez, F. (2016). Caracterización mineralógica detallada en el depósito de $\mathrm{Cu}-\mathrm{Au}$ Cerro Corona - La clave fundamental para la geometalúrgia y la optimización de procesos. XVIII Congreso Peruano de Geología (2016), 1-4. http://www. goldfields.com.

Cambefort, H. (1968). Perforaciones y Sondeos. Ediciones Omega. https://www.libros-antiguos-alcana.com/henricambefort/perforaciones-y-sondeos/libro

Cánepa Iannacone, C., \& Manzaneda Cabala, J. (2005). La microscopia ópticay los procesos metalúrgicos-Aplicaciones en casos peruanos. Instituto de Ingenieros de Minas Del Perú. XXVII Convención Minera. https://es.scribd.com/ document/273699289/C-canepa-Microscopia-Optica-enLos-Procesos-Metalur

Carrión Osnayo, C. (2018). Aplicación de redes neuronales artificiales para la predicción de la recuperación de planta concentradora en Minsur S.A. - Unidad San Rafael [Universidad Nacional de San Agustín, Arequipa]. http:// repositorio.unsa.edu.pe/handle/UNSA/6629

Dominy, S. C., O'connor, L., Parbhakar-Fox, A., Glass, H. J., \& Purevgerel, S. (2018). Geometallurgy-A route to more resilient mine operations. In Minerals (Vol. 8, Issue 12, p. 560). MDPI-Multidisciplinary Digital Publishing Institute. https://doi.org/10.3390/min8120560

Guthrie, M. (2019). Ore sorting - Preceding processing $\mid$ Ausenco. International Mining (IM). https://www.ausenco.com/en/ ore-sorting-preceding-processing

GVMapper. (2020). Sistema de información geográfica. Total Data Capture. intuitive - fast - reliable. Geovectra. https:// es.scribd.com/document/288615547/GVMapper

Klaus Schwab. (2017). La cuarta revolución industrial-The Fourth Industrial Revolution. Foro Económico Mundial. $\mathrm{http} / / / 40.70 .207 .114 /$ documentosV2/La cuarta revolucion industrial-Klaus Schwab (1).pdf

Koch, P.-H. (2019). Computational methods and strategies for geometallurgy. In Luleå University of Technology (Ed.), Doctoral thesis / Lulea University of Technology 1 jan $1997 \rightarrow$... Department of Civil, Environmental \& Natural Resources Engineering Division of Minerals and Metallurgical Engineering. www.ltu.se

Manzaneda Cabala, J. R. (2010). Aplicación de microscopía en el procesamiento de minerales por flotación [Universidad Nacional de Ingeniería]. http://cybertesis.uni.edu.pe/handle/ uni/611 
McCoy, J. T., \& Auret, L. (2019). Machine learning applications in minerals processing: A review. In Minerals Engineering (Vol. 132, pp. 95-109). https://doi.org/10.1016/j. mineng.2018.12.004

Meza, J., \& Núñez, B. (2018). Estudio geometalúrgico para optimizar el circuito de flotación separación plomo-cobre en la planta concentradora U.M. Cerro Lindo [Universidad Nacional del Centro del Perú]. https://alicia.concytec.gob.pe/vufind/Record/UNCP c57a242641a101d40b6b10de7c03a89b

Romero, F., Yacher, L., \& Bascur, O. A. (2006). Extended semiautogenous milling: Smooth operations and extended availability at C.M. Doña Ines de Collahuasi SCM, Chile. 2006 SME Annual Conference - Advances in Comminution, 2006, 181-190. https://www.researchgate. net/publication/289103458_Extended_semiautogenous milling Smooth operations and extended availability at_CM_Dona_Ines_de_Collahuasi_SCM_Chìle
Simon, A. (2007). Control Sample Insertion Rate: Is There an Industry Standard? June, 9. https://es.scribd.com/ document/75630300/Simon-Armando-Text-Controlsample-insertion-rate-is-there-an-industry-standard

Transmin MC. (2020). Características del Software Cancha Geometallurgy. http://www.cancha.pe/

Yahyaei, M. (2020). Mineral processing challenges and future directions. SMI-JKMRC. https:/es.scribd.com/ document/411166634/Mineral-Processing-Challenges 
